\title{
Aprender de modo autónomo en la universidad: una experiencia dentro de la asignatura de Antropología y Sociología del Arte con estudiantes de Bellas Artes

\author{
Learning autonomously at university: an experience within the subject \\ of Anthropology and Sociology of Art with students of Fine Arts
}

\author{
Fernando Herraiz García \\ Pedagogías Culturales / Facultad de Bellas Artes \\ Universidad de Barcelona \\ C/ Pau Gargallo, 4, 08028, Barcelona \\ f.herraiz@ub.edu
}

\begin{abstract}
Resumen
El texto presenta una experiencia de aprender con estudiantes de Antropología y Sociología del Arte, asignatura de carácter obligatoria del primer año del grado en Bellas Artes. Considerando los cambios académicos que experimentan los estudiantes al iniciar sus carreras académicas, el curso planteó algunas estrategias de aprender de modo autónomo yendo más allá de los contenidos prescritos; para ello, por un lado, se propuso centrar el curso en los temas de interés de los estudiantes, y por otro, se les colocó en el lugar de investigadores que aprenden a partir de sus propias vivencias. Esta labor se desarrolló dentro de una perspectiva autoetnográfica de investigación asumiendo cuestiones que les situaban dentro del contexto social del arte vividas en primera persona. En este sentido, el presente artículo muestra la experiencia desde una doble dimensión: por un parte, aquella relacionada con los dilemas metodológicos y el papel de los estudiantes como autores de sus propios estudios; y por otro, una dimensión reflexiva en torno a aspectos de la sociología del arte puestos en cuestión desde la asignatura.
\end{abstract}

Palabras clave: Aprender autónomo, Sociología del arte, Autoetnografía, Relaciones pedagógicas, Educación artística.

\begin{abstract}
The text presents a learning experience with students of Anthropology and Sociology of Art, a required course for the first year of the Fine Arts degree. Considering the academic changes faced by students at the start of their academic careers, the course offers some strategies for autonomous learning that go beyond the set content. To do so, on the one hand, there was a proposal to center the course on the interests of the students and, on the other, to place them in the role of researcher learning through their own experiences. This work was developed within an autoethnographic perspective of research, taking on questions that situated them within the context of social art lived in first person. In this sense, this article shows the experience from two dimensions: the first, related to methodological dilemmas and the role of the students as authors of their own studies and the second, a reflexive dimension with respect to aspects of the sociology of art put into question through the subject.
\end{abstract}

Key words: Autonomous learning, Sociology of art, Autoethnography, Pedagogical relationships, Artistic education.

\section{El contexto de la investigación}

Hace algún tiempo, la revista Cuadernos de Pedagogía me encargó la reseña del libro de Bill Johnston (2013) con el título El primer año de Universidad. Una Experiencia positiva de transición. El texto, que leí con avidez, versaba sobre experiencias de aprendizaje en el primer año de formación universitaria comprendiendo que, dicho período, es especialmente relevante para el éxito académico. Y esto es así 
porque son nuevos los desafíos que deben encarar los estudiantes al transitar por cambios académicos, sociales, culturales y personales. Frente a este hecho, Johnston (2013) reclama la necesidad de asumir compromisos institucionales y docentes que replanteen y estimulen la labor en esta línea; y es que, paradójicamente, el aumento de trabajo que vienen asociados a dichos grupos, acarrea la disminución del tiempo de dedicación a la investigación reduciendo el estatus y las expectativas profesionales de docenteinvestigador.

La lectura del texto de Johnston (2013) adquiría significado para mí porque, para bien o para mal, la implementación del Plan Bolonia me había comportado impartir docencia en una asignatura de primer año en diversos grupos de los Grados de Bellas Artes, de Diseño, y de Conservación y Restauración de Bienes Culturales en la Universidad de Barcelona. Pasaba de trabajar en asignaturas de segundo y tercer curso en la licenciatura de Bellas Artes, a dar Antropología y Sociología del Arte a estudiantes recién llegados de diversos bachilleratos; en mi caso, a impartir las sesiones que dedicamos únicamente a la sociología del arte.

Si bien es cierto que el texto fue uno de los detonantes que motivó mi trabajo, por otro lado, debo decir que, ante la experiencia de aprender que voy a narrar, venía trabajando en diversos proyectos dentro del Grupo de innovación docente para favorecer la indagación (Indaga-t). Formar parte de este equipo me permitía reflexionar sobre mi práctica docente poniendo en cuestión las posiciones que asumía y colocando el foco en las relaciones pedagógicas emergentes en el aula.

El artículo que ahora presento habla de las experiencias de aprender que construimos estudiantes de primer año y yo (como docente) dentro de la asignatura Antropología y Sociología del Arte, teniendo como marco de indagación el proyecto La evaluación en el aprendizaje autónomo (PID2012-UB/040) desarrollado por el grupo Indaga-t.

\section{Relaciones iniciales entre los estudiantes y la asignatura}

Desde que estoy trabajando en cursos de primer año, en los estudiantes del grado de Bellas Artes he detectado diversidad de posiciones ante la asignatura de Antropología y Sociología del Arte. Éstas transitan desde la resistencia a los conocimientos que en ella se imparten por un extremo, a posiciones de afinidad que asumen los cambios como desafíos a hacer frente para seguir aprendiendo. A aquellos que se resisten, les percibo cómodos valiéndose del reconocimiento que han disfrutado en contextos pre-universitario; quizá las destrezas manuales adquiridas a lo largo de su formación, y el dominio de diversas técnicas artísticas sean los fundamentos en los que sostienen sus posiciones. Sea como fuera, cada inicio de curso, me sorprendo tratando de convencer de las "pros" de la asignatura, como si de un 'vendedor' se tratase, a estudiantes más motivados en aquello que les puede aportar los talleres a su vida académica. Con frecuencia, veían en la componente teórica un discurso enredado entre argumentaciones de otras disciplinas que poco tenían que ver con el arte.

En el juego de las motivaciones parecía estar el dilema de las resistencias; un dilema que giraba en torno al problema que supuestamente distingue el carácter de los cursos entre dos ámbitos: entre lo teórico y lo práctico en el arte. Paradójicamente, la asignatura era vista por los estudiantes por su carácter teórico, a pesar de que Antropología y Sociología del Arte venía definida como teórico-práctica dentro de los planes docentes. Mi lugar ante el problema intentaba romper con dicha dualidad, desarrollando estrategias que, mediante el diálogo reflexivo, hiciese fluir los temas emergentes propios del curso ${ }^{1}$ a través de la

\footnotetext{
${ }^{1}$ La asignatura trata de problematizar nociones sociales dominantes en torno a las artes, tomando conciencia de la propia situación del estudiante dentro de la redes de relaciones sociales vinculadas con: el mercado, el sistema del arte, la identidad del artista, las artes populares, la cultura de masas, etc.
} 
realización de trabajos visuales y textuales. Todo ello, para tratar de favorecer miradas críticas en torno a la construcción social de las artes visuales y las relaciones socio-culturales que la configuran.

\section{En torno al trabajo de innovación docente. El trabajo evaluativo en el aprender autónomo}

Dentro del proyecto La evaluación en el aprendizaje autónomo (PID2012-UB/040) propusimos desarrollar un trabajo educativo que nos permitiese reflexionar a partir de tres dimensiones: (3.1) el papel del docente y de los estudiantes, (3.2) la transformación de la experiencia en producción y autoría, y (3.3) la relación entre el aprendizaje y la evaluación.

\subsection{El papel de los docentes y estudiantes}

Redefinir el papel de los docentes y discentes dentro de una experiencia autónoma, tal como afirma Chan (2000), implicaba desplazar el foco de interés hacia las consideraciones significativas de los estudiantes. El docente debía favorecer modos de aprender colaborativos y acompañar los procesos críticos y autoreflexivos que surgiesen de la interpelación entre los estudiantes (Champagne, Clayton, Dimmitt, Matthew, Savage, Shaw, Stroupe, Thein, y Walter, 2002). Trabajar en esta línea, según Kenny (1993), conllevaba la necesidad de plantear cuestiones que motivasen y colocasen a los estudiantes a través de preguntas como: ¿quiénes eran?, ¿qué pensaban?, o ¿qué les gustaba?. De no ser así, las posiciones asumidas estarían alejadas de propuestas de transformación y cambio cultural y social.

Al redefinir mi papel como profesor, el dilema emergía cuestionándome el grado y las cualidades del acompañamiento que asumía. Al respecto, me sentía motivado en el papel del diseñador de ámbitos donde aprender, favoreciendo así la producción de conocimientos (Marcelo, 1995); pretendí emplazarme cercano a la figura del sujeto auto-reflexivo ${ }^{2}$ que contemplaba y cuestionaba los discursos como dispositivos histórico-socialmente situados dentro de la tradición post-crítica (Cascante, 2004).

\subsection{Experiencias de producción y autoría}

Transformar la experiencia en producción y autoría implicaba reconocer los procesos individuales y colectivos de elaboración y transformación de los conocimientos en el que, el papel de los estudiantes, fuese significativo por asumir compromisos en el proceso. Revisar las aportaciones de Kenny (1993) ${ }^{3}$ y Chan $(2000)^{4}$ sobre al aprendizaje autónomo, me llevó a tener presente cuatro dimensiones: la colaboración, el desarrollo, la evaluación y la divulgación.

\footnotetext{
${ }^{2}$ Cascante (2004), al reflexionar sobre la formación inicial del profesorado, realiza una aproximación a las tradiciones educativas en términos discursivos vinculándolos a modos de comprender la identidad del docente; en esta línea, define: (a) el sujeto liberalilustrado dentro de la tradición académica, (b) el sujeto entrenado en competencias dentro del discurso técnico, (c) el sujeto reflexivo en y sobre la acción dentro del discurso práctico, (d) el sujeto reflexivo, más allá de la acción, cuestiona la institución desde una tradición crítica, y (e) el sujeto auto-reflexivo que examina los discursos como dispositivos situados en la historia y la sociedad dentro de una tradición post-crítica.

${ }^{3}$ Kenny (1993) ordena una serie de objetivos para que los estudiantes aprendan de modo autónomo: (1) iniciar el trabajo, (2) planificar, organizar y llevarlo a cabo, (3) ser capaces de argumentar el porqué de lo que se está haciendo, (4) ser capaces de entender los que los compañeros argumentan cuando hablan y escriben acerca de lo que están haciendo, (5) examinar su propio trabajo críticamente, (6) examinar el trabajo de otros estudiantes, (7) clarificar las ideas de forma oral y escrita, (8) usar los medios de comunicación a la hora de clarificar las ideas y de desarrollar el trabajo, (9) obtener información relevante de otras personas, y (10) cooperar con otras personas compartiendo estrategias.
}

${ }^{4}$ Chan (2000) afirma que se favorece el trabajo autónomo siguiendo las fases siguientes: (a) establecer los objetivos del aprendizaje, (b) identificar y desplegar estrategias para conseguir dichos aprendizajes, (c) desarrollar el plan de estudios, (d) identificar y crear recursos y soportes adecuados, y (e) evaluando su propio progreso. 
1. La colaboración, en cuanto a la planificación y la organización, debía ser una cualidad que caracterizase la estrategia de trabajo. Los estudiantes debían ser capaces de: establecer los objetivos, entender y aportar argumentaciones, reconocer sus ubicaciones y tránsitos, examinar y comprender el trabajo propio y el de los demás compañeros, clarificar ideas de forma conjunta, cooperar en las iniciativas propuestas por el grupo, etc.

2. El desarrollo de conocimientos y saberes estaría vinculado con las realizaciones producidas individual y colectivamente, donde los estudiantes serían autores de los materiales y artefactos elaborados. El trabajo autónomo debía favorecer: el diálogo y la obtención de información en diversas fuentes, la construcción de sentido a partir del diálogo con información relevante, la identificación y el uso de recursos apropiados para la construcción de conocimientos, el desarrollo de nuevos materiales, etc.

3. La evaluación sería entendida como la devolución y retroalimentación de manera dialógica entre los agentes implicados (estudiantes, docentes y colaboradores externos). Yendo más allá de la mera calificación numérica, esta tarea tendría que ver con: la reflexión crítica de la propia experiencia de aprendizaje y la de los demás, la comprensión de los tránsitos realizados individual y grupalmente, el reconocimiento de las nuevas ubicaciones, la confección de nuevos dilemas y preguntas, etc.

4. La divulgación se comprende como toda labor vinculada con su extensión dando cuenta del trabajo y los procesos desarrollados; es en este ámbito donde se realiza el presente texto, mostrando, en este caso, -bajo mi mirada docente-, la aportación de los estudiantes a la experiencia de enseñanza y aprendizaje.

\subsection{Entre el aprendizaje y la evaluación}

La evaluación como forma de seguir aprendiendo debía ser una experiencia de acompañamiento si pretendía ser consecuente con la posición que asumía. Desmarcándose de la mera calificación numérica, debía ser colectiva e individual construida a través del diálogo y la reflexión colaborativa, y llevada a cabo multidireccionalmente en cualquier momento del curso; debía tener carácter reflexivo cuestionando el propio proceso de aprender y las tomas de decisiones emprendidas en todo el proceso.

\section{El inicio del curso. Desplazando el foco hacia el interés de los estudiantes}

Comenzamos el curso realizando una aproximación a la noción de sociología y a algunas aportaciones que se habían realizado al campo disciplinar desde otras áreas de conocimiento. A la estela de Estruch (2003) nos acercamos a sus orígenes y las características principales de una perspectiva sociológica. Con Zolberg (2002) comprendíamos el ámbito de estudio a partir de la discrepancia entre dos posiciones: la perspectiva interna centrada en la obra, y la externa propia de una sociología interesada en el contexto social del arte. Heinich (2003) nos llevaba a vislumbrar el enfoque comprehensivo que desde una mirada crítica trataba de ir más allá de modelos explicativos. Con la aportación de Bourdieu y Darbel (2003) reflexionábamos en torno al papel de la investigación sociológica dentro de contextos museísticos, etc.

Presentar el armazón teórico que sustentaba la asignatura ayudaba a hacer visible la distancia entre los contenidos del curso y las posiciones de los estudiantes; si pretendía favorecer el aprender de modo autónomo, la desconexión entre la historia social del arte ejemplificada y las experiencias propias se convertía en un problema.

Hacer frente a dicho dilema me hizo reflexionar en torno a: ¿cómo desplazar el foco de interés hacia consideraciones significativas de los estudiantes? Entonces mi labor como docente viró; más que despertar el interés de los estudiantes por los contenidos de la asignatura, consistió en averiguar qué hacer para que el curso se "interesase" por los conocimientos de los estudiantes. Y para ello, como argumentaba Kenny 
(1993), era importante conocer quiénes eran, qué pensaban y qué deseaban los sujetos con los que iba a trabajar.

Pronto vislumbré que este giro rompía con la noción de currículum entendida como contenido o planificación educativa; comprenderlo como realidades interactivas (Angulo, 1994) me llevaba, más que a despertar intereses cruzados, a entender que los estudiantes (en cuanto a lo que conocían), los contenidos de la asignatura (en relación a lo que ya era conocido) y yo como docente (en el papel de diseñador de espacios de aprender de lo que todavía no conocíamos) formamos parte integral de los procesos curriculares tal como afirmaban Clandinin y Connelly (en Angulo, 1994). Así fue cómo los contenidos previos de la asignatura se alteraban relacionándose con otros conocimientos propios y situados dentro del contexto de los estudiantes.

Para ser consecuente con la posición que iba a adoptar, formulé algunos ajustes docentes (Marshall y Drummond, 2006) o decisiones informadas (Chan, 2000) ${ }^{5}$ que colocaban la asignatura bajo una epistemología narrativa construccionista propia de la investigación autoetnográficas.

Autoethnographers argue that self-reflexive critique upon one's positionality as researcher inspires readers to reflect critically upon their own life experience, their constructions of self, and their interactions with others within sociohistorical contexts (Ellis \& Bochner, 1996; Goodall, 1998). (...) Performing autoethnography has allowed me to position myself as active agent with narrative authority over many hegemonizing dominant cultural myths that restricted my social freedom and personal development, also causing me to realize how my Whiteness and class membership can restrict the social freedom and personal development of others. (Spry, 2001, p. 711)

La propuesta autoetnográfica nos permitiría trabajar bajo dos dimensiones: por una parte, colocaba a los estudiantes en el lugar del investigador y, por otra, daba sentido al curso aprendiendo de sus propias experiencias. Trabajar en esta línea, tenía el objetivo de reflexionar críticamente en torno a los mundos del arte por los que habían transitado cuestionando sus miradas en torno a aquello que dábamos por sentado, y conectando sus autobiografías con la cultura, la sociedad y la política (Ellingson y Ellis, 2008).

Para iniciar la propuesta sólo quedaba plantear una pregunta que les colocase en el epicentro del estudio a la vez que estuviese dentro de los propósitos del curso. Primeramente, debería estar dirigida a "intentar comprender globalmente (los fenómenos artísticos) a partir de sus conexiones con otros aspectos de la realidad social" (Furió, 2012, p. 21); por otra, también, debería estar abierta a sus vivencias y al contexto social más próximo. La pregunta con la que iniciábamos el trabajo fue: ¿cómo habían venido relacionándose con las artes a lo largo de sus trayectorias de vida?

\section{La asignatura como proceso. Algunos momentos claves y experiencias de aprender}

Ordenar y reflexionar sobre el proceso de aprender durante aquellas sesiones, me llevó a distinguir cinco momentos significativos: (5.1) compartiendo experiencias e imágenes en tiempo de clase, (5.2) escritura de un informe autoetnográfico, (5.3) devolución a los estudiantes de sus trabajos, y (5.4) investigar con las investigaciones de los estudiantes.

\subsection{Compartiendo experiencias e imágenes sobre nuestra relación con el arte en el aula}

Tras consensuar el giro autoetnográfico que iba a tomar la asignatura y lanzar la pregunta inicial con la que trabajaríamos, como punto de partida, decidí aportar una imagen propia y relatarla a nivel discursivo a modo de ejemplo.

\footnotetext{
${ }^{5} \mathrm{Al}$ reflexionar en torno a la intervención docente en el aprendizaje autónomo, Marshall y Drummond (2006), referenciando a Perrenound (1998), habla de ajustes, y Chan (2000) de decisiones informadas. Al respecto, la labor del docente debe favorecer el proceso comprendiendo que las nuevas responsabilidades asumidas por los estudiantes deben ser acompañadas por las suyas.
} 
En la fotografía, fechada en 1980, yo aparecía a la edad de trece años junto a otros compañeros recibiendo clase de pintura al óleo. A partir de la imagen pudimos discutir sobre: la noción de arte vinculada a la representaciones de paisajes y bodegones, los modos de aprendizaje basados en la copia, y las políticas culturales que favorecían determinadas actividades extra-escolares dirigidas a niños y jóvenes. Mientras que algunos estudiantes se veían reflejados en la imagen, se problematizaba la noción de arte por la falta de consenso dentro del grupo. El sentido común era, también, el menos común de los sentidos cuando se discutía en torno a cómo se debería enseñar arte, poniendo en tela de juicio la copia como una estrategia eficaz de aprendizaje. La discusión, que por momentos se acaloraba, fue útil para comprender el papel de las políticas culturales al promover determinadas formas de aproximarse el arte, por un lado, y configurar subjetividades relacionales, por otro. No en vano, aquellos talleres de pintura se convirtieron en un lugar de encuentro donde jóvenes compartían espacio desde la afinidad con maestros que, desde el voluntariado, enseñaban en su tiempo de ocio. La escuela de arte a la que asistía por aquel entonces fue inaugurada cuatro años antes como consecuencia de las políticas culturales desarrolladas con el primer ayuntamiento democrático de mi ciudad.

Aquella imagen fue el detonante para que los estudiantes aportasen elementos auto-biográficos significativos para la reflexión crítica. En esta línea, indagar en sus relaciones con el arte (en un sentido amplio), llevó a: Sara a aportar una imagen suya cuando tenía seis años de edad embelesada coloreando sobre un papel el logotipo del Club Súper 3; María a presentar una fotografía cuando era niña admirando perplejamente un cuadro en un mercadillo de arte; Martina a hablarnos de una fotografía de ella garabateando con tizas de colores el suelo de una cancha de baloncesto con poco más de 2 años de edad; Pere a mostrar una imagen propia pintando para una asignatura de la facultad, etc. El carácter discusivo de las imágenes comportó la realización de un mapa visual de modo colectivo relacionando las experiencias individuales y colectivas con los contextos sociales y culturales de cada estudiante.

Las conversaciones que se generaron nos ayudó a comprender que, básicamente, las posiciones que habían venido asumiendo eran dos: la de público y la de autor. Como público, en su papel de admiración y reconocimiento de la obra artística; y como autor, desde una función dominantemente práctica implicada en el desarrollo de destrezas en la realización de representaciones visuales. Todo ello, llevado a cabo en el espacio del hogar y en ámbitos públicos vinculado con concursos de dibujo, espacios de formación y de ocio. Prácticamente todos los estudiantes recodaban haber crecido viendo, sobre sus cualidades artísticas, la mirada motivadora de reconocimiento de adultos, amigos y compañeros de pupitre.

Como consecuencia de este primer acercamiento detecté que el curso devino hacia una sociología de la educación artística, dejando atrás una sociología del arte en un sentido tradicional. En este sentido, empezábamos a reconocer el papel de la cultura visual en la formación artística a través de la imagen de Sara dibujando el logotipo del Club Súper 3; a reflexionar sobre los espacios de mercado y las relaciones que favorecían a partir de la imagen de María; a reconocer la función social que jugaba el arte en el tiempo de ocio de Martina garabateando sobre en el suelo de una cancha; a cuestionar la imagen del artista de caballete con la imagen de Pere, etc. Un poco alejado en el tiempo nos quedaban las relaciones de aprendizaje emergente en la Academia del Disegno de Vasari en la Florencia o la Accademia di San Luca en Roma de Zuccari en el siglo XVI, o la formación humanista integral que parecía dominar la formación de artistas en el renacimiento, o la reglamentación de la carrera artística en la Francia que pautó los Salons en los siglos XVIII y XIX. A pesar de la distancia en el tiempo y lugar había inercias que parecían estar vivas en algunos comentarios de los estudiantes.

\subsection{Escritura del informe autoetnográfico}

Continuar trabajando en esta línea implicaba hacer frente a un desafío de orden metodológico. El dilema radicaba en cómo las argumentaciones de los estudiantes transitaban entre hablar de si mismos por un lado, y hablar desde ellos mismos por otro. Hablar de si mismos, colocaría al discente en el lugar del narrador de historias que colabora en una investigación; en cambio, hablar desde si mismos implicaría ubicarse 
como investigadores, dando sentido a la propia experiencia de un modo autónomo y crítico desde una metodología autoetnográfica. Dicho giro se consolidó cuando decidí negociar la posibilidad de que el trabajo final tratase de ser una prolongación de aquello que veníamos realizando durante las sesiones. La propuesta fue aceptada por el grupo y los estudiantes iniciaban la preparación de un texto autoetnográfico que situase la experiencia reflexionando en términos sociológicos alguno de los temas surgidos en las conversaciones y cartografías visuales que se habían realizado.

La extensión de la componente textual del informe final no debía de exceder las cinco páginas, mientras que la componente cartográfico-visual podía adquirir el formato y tamaño deseado por el alumno.

Contaron con varias semanas para realizar el trabajo; durante las mismas tutoricé algunos encuentros individuales y grupales con la sensación de que, como docente -más que orientar-, me dedicaba a validar, autorizar y legitimar la plasmación crítica de sus experiencias en textos académicos. El origen de la inquietud que percibí quizá se encontraba en el lugar donde yo les había colocado reconociéndoles como autores de sus propios textos; un lugar que, por ser poco habitual en sus trayectorias, les eran tan nuevo como incierto.

\subsection{Evaluación de los textos de los estudiantes}

Después de finalizar las sesiones del curso, colocarme en el lugar del evaluador fue algo controvertido y divergente. La controversia surgía del hecho de haber participado en los debates en clase y orientado las tutorías como uno más (al menos así me sentí yo); y es que al evaluarles también juzgaba mi contribución al curso. De algún modo, no me sentía legitimado dado el alto grado de implicación que asumí; ciertamente, el problema se acrecentaba cuando pensaba en cómo traducir la evaluación en la calificación final que debía complementar en las actas de los estudiantes.

Por otro lado, el carácter divergente se acentuaba al iniciar la lectura de los textos tomando conciencia de dos componentes. La primera e inmediata tenía que ver con el valor reflexivo autoetnográfico que, como estudiantes-investigadores, profundizaban en temáticas y daban respuestas a las preguntas planteadas. La segunda componente surgía sin pretenderlo y estaba relacionada con las experiencias que, como estudiantes, aportaban autobiográficamente al campo de estudio; en este sentido, no podía evitar abandonar mi papel docente para colocarme como investigador y acercarme a los relatos de los estudiantes como si de evidencias se tratasen. Así pues, el dilema que me supuso la evaluación transitaba entre las dos componentes priorizando sobre la cualidad autoetnográfico dado que era lo negociado a priori; y en los márgenes, la vertiente autobiográfica más descriptiva se convertía en fuente de inspiración para seguir aprendiendo con los estudiantes.

Finalmente, mi lectura divergente confluyó en un informe individual dirigido a los estudiantes en los que era difícil distinguirme como docente o como investigador. La devolución se movía a medio camino entre las cuestiones que los estudiantes habían abordado, y las temáticas que, desapercibidas, mi mirada supuestamente más "experta" hacía emerger; y es que continuaba aprendiendo incluso con los trabajos menos idóneos.

\subsection{Aprendiendo con las investigaciones de los estudiantes}

La revisión de los trabajos de los estudiantes corroboró lo que ya había sospechado durante las sesiones de trabajo: una distancia significativa entre los previstos de la asignatura y las colocaciones que habían asumido a lo largo de trayectorias de vida de los estudiantes. La sociedad que contextualizaba la Accademia di San Luca en la Roma del siglo XVI, o la formación de artistas en el renacimiento, o la carrera artística en los Salons franceses en los siglos XVIII y XIX, poco tenía que ver con la sociedad actual. El acceso a la formación universitaria, una economía neoliberal imperante, el desarrollo de las nuevas tecnologías de la información y la comunicación, etc. provocaba que las miradas y posiciones fuesen distintas. En esta 
línea, dieron cuenta de ello los cincuenta estudiantes a través de sus textos; reflexionar en torno a los modos de relacionarse con el arte no sólo les ubicaba dentro del curso, sino que también mostraba un mapa amplio de temas y experiencias de interés para sus carreras académicas. Confluyendo las consideraciones de estudiantes-investigadores y la mía como docente-investigador, emergieron básicamente cuatro dimensiones de análisis: (5.4.1) Miradas de identificación y motivación, (5.4.2) Algunas experiencias de consolidación y controversia en la formación artística reglada, (5.4.3) Transitando por espacios de enseñanza artística no reglada, y (5.4.4) Más allá de las artes visuales.

\subsubsection{Miradas de identificación y motivación}

En la lectura de los trabajos finales me vi reflejado en algunas de las experiencias de los estudiantes; desde la infancia, a igual que ellos y ellas, reconocía en la mirada de los demás (familiares, compañeros de pupitre, docentes, etc.) la "(ad)miración" por las destrezas que tenía a la hora de "dibujar" como si de una habilidad innata se tratase. En este sentido, el juego de miradas mediaba en la ubicación donde el sujeto era colocado por el otro, e influía en la posición asumida por uno mismo. Las argumentaciones de Emily y Júlia fueron dos de los diversos ejemplos que en esta línea emergieron.

El arte para mí en gran parte fue una escapatoria y podía ser un elemento socializante cuando quise en primaria y en secundaria, las otras chicas de clase me reconocían como la artista del colegio y me pedían que les hiciera dibujos y que las retratase, llegaba a servir para unirme más a los demás ayudaba a integrarme mejor en diferentes grupos de personas pero a su vez era un elemento marginante que distanciaba y con lo que evadía del lugar y del tiempo donde estaba. El arte para mí es una forma de unir lo que siento con lo que veo y viceversa. "la realidad de la vida cotidiana es una realidad intersubjetiva, es decir una realidad compartida con otros, pero nunca compartida por completo. Esto es precisamente lo que hace que tengamos cosas que decirnos y comunicarnos" (Estruch, 2003, p. 41). (Emily)

Una anécdota (...) que también recordaré siempre fue el día en que la directora subió a la clase a felicitarme en persona por un autorretrato que había hecho. Supongo que para mí el arte siempre ha significado descanso y libertad, y que poco a poco se convirtió en motivación; todos tenemos un punto fuerte y el mío era el dibujo. Mis padres así lo vieron rápidamente, entonces me ofrecieron apuntarme a una academia y yo, sin dudarlo, dije que sí. (Júlia)

También era significativa la motivación encontrada en el ámbito familiar. En ocasiones porque realizaban actividades compartidas que les llevaban a visitar museos y exposiciones; en otras, la complicidad encontraba su origen en los padres y madres con estudios universitarios (Bellas Artes e Historia del Arte), o en el hecho de que algún familiar (abuelos, padres, madres, hermanos, etc.) tuviese cierto tipo de trayectoria artística dentro del ámbito de la producción.

En mi caso, esta predisposición por dibujar y pintar surgió desde pequeña como entretenimiento, un hobby, el cual se acentuó debido a la afición de mi abuelo por la pintura, el dibujo y la escultura, lo que me hizo crecer en un ambiente donde tenía materiales y herramientas para utilizar cuando quisiese, (...) Gracias a esto pude observar lo que él hacía, cómo trabajaba, con qué pintaba y qué dibujaba. (Marina)

También pasamos mucho tiempo en Londres y otros lugares de Inglaterra donde nos alimentaban los museos de arte con el Tate, el National Portrait Gallery, el de ciencias y de historia el cual era mi preferido (Emily)

Antes de que yo naciese, mi padre solía pintar cuadros al óleo, así que en parte el amor que le tengo al arte es por eso. Mi casa está llena de cuadros suyos e inconscientemente creo que eso me ha influenciado. Recuerdo alguna tarde en la que pintaba en la tarraza con mis padres, eran momentos en familia muy especiales. (Marta)

El reconocimiento de los demás era un elemento clave que avocaba a recorrer determinados tránsitos de formación y a construir miradas de deseo e interés. La relación con el arte de Marta, Marina, Emily y Júlia se manifestaba como un medio de evasión, libertad, emotividad, sentimiento y motivación. En esta misma línea, Anna recodaba la experiencia de producción artística como una necesidad vital. 
Dibujar ha sido siempre mi pasión, y no lo digo solo por decir, porque estudio Bellas Artes y se da por hecho que me gusta. Ni tan sólo soy consciente de si realmente tengo talento para esto; sólo sé que sin lo que hago no podría vivir. (...) Quizá soy demasiado extremista en este aspecto, pero soy incapaz de pasar un solo día sin dibujar o construir cualquier cosa, aunque sea un garabato o un retrato con el seis y el cuatro. (Anna)

Al respecto, no eran las únicas que escribía usando términos similares: Olga y Sílvia lo hacía hablando de amor, Martina y Pierina de pasión, Paula de diversión y atracción, Júlia y Joan de amor y odio, Paula y Paloma de diversión y disfrute. Dentro del grupo, dominantemente, las posiciones se situaron dentro de los márgenes que comprenden el arte como autoexpresión creativa.

\subsubsection{Algunas experiencias de consolidación y controversias en la formación artística reglada}

La experiencia recordada por Júlia en la que, la directora del centro, halagaba sus autorretratos, era uno de tantos ejemplos de miradas de reconocimiento que consolidarían posiciones en los estudiantes en torno al arte. Eran miradas de complicidad que mediaban en las trayectorias y las prácticas dentro de la comunidad escolar. Similar a Júlia, Marta también recordaba distinguirse entre sus compañeros de aula por sus habilidades en clase de Educación Visual y Plástica.

Cuando llegué a sexto de primaria, recuerdo que todo el mundo me elogiaba a la hora de hacer trabajos manuales y dibujos en las clases de plástica, y por ello el profesor me escogía a mí a otra compañera más para ayudar a decorar el pasillo de la escuela en días puntuales de otoño o primavera. (...) Durante los cuatro años de la ESO, era reconocida muchas veces por mi manera de pintar, recuerdo que muchas compañeras me decían "Marta, dibujas muy bien, ¿cómo lo haces? (Marta)

Paradójicamente a las miradas motivadoras en la escuela asignando posiciones y roles, emergían contradicciones que hablaban de ciertos desprestigios de los conocimientos artísticos en la enseñanza secundaria obligatoria. Mientras que Martina se hacía eco de la voces que consideraban dichos conocimientos como poco serios, Anna recordaba que "estudiar cualquier arte, para mucha gente es inferior a estudiar ciencias o económicas". Este conflicto lo corroboraba Robert al dar cuenta de las consideraciones que tuvo que hacer frente al decidir qué itinerario estudiar.

Cuando llegué a cuarto de la ESO, tenía que escoger entre tres itinerarios por cursar. El A (científico), B (Social), C (artístico). Yo tenía muy claro que quería hacer, y mi familia también sabía cuál era mi preferencia. En casa se discutió el tema, era un momento decisivo en mi vida, tenía que comenzar a ubicarme y pensar en mi futuro. Al principio mi madre no estaba segura de que hiciese el itinerario C, estaba mal visto, era el itinerario donde se apuntaban muchos de los que no tenían interés por nada; era visto como el itinerario de los vagos. También surgió el tema económico y las salidas profesionales. Mi madre tenía miedo de que en un futuro hubiese estudiado una cosa inútil y que no pudiese tener un salario digno en un futuro. (Robert)

De las palabras de Robert, comprendo que las trayectorias y las decisiones tomadas no fueron fáciles dado que las expectativas construidas en su entorno no eran del todo alentadoras. Algunas de las miradas de complicidad mutaban al considerar la precariedad laboral asociada a los mundos del arte en general, y a la vida del artista en particular. A pesar de todo, Robert cursó el Bachillerato Artístico, una vez iniciado el Social, después de un encuentro entre los padres y una de las profesoras de artes de su instituto. En este caso, el papel docente fue el detonante para continuar su formación artística. Pero no siempre las relaciones pedagógicas son de un sugerente acompañamiento; como muestra de ello, el comentario que recoge Anna:

Decidí ignorar las amenazas de mi profesora de matemáticas, quien me decía diariamente que yo no haría nada en la vida y que, como muchos otros, acabaría trabajando en un Mc Donald's (Anna)

Anna recordaba las palabras de una profesora que repetidamente le invitaba a dejar las artes si pretendía "hacer algo en la vida". Dichas palabras ponían en evidencia miradas que colocaban al conocimiento artístico en un estatus inferior, así como bajo sospecha el porvenir de una carrera en esta línea. 
Quizá el origen del comentario de la docente se encuentre en los privilegios que disfrutan determinadas áreas dentro del currículum escrito; y es que, tal como decía Goodson (1991), éste se encarga de la asignación de recursos, de la distribución profesional y de la atribución de estatus de conocimiento, priorizando sobre aquellas materias que califican a sus estudiantes de un modo numéricamente cuantificable. De esta controversia se hace eco Silvia cuando, en su trabajo para la asignatura, argumentaba:

Este tema se ve claramente en la educación actual, en la que cada vez se están reduciendo más las asignaturas de arte en las enseñanzas obligatorias porque se decide que son más importantes las del ámbito científico. (...) Según el pedagogo Christopher Clouder "Sabemos que los niños con buena base en artes tiene tres veces más posibilidad de estudiar en la universidad. También hay estudios que reflejan que los resultados académicos de un joven que se le haya formado en artes son entre un $20 \%$ y $30 \%$ mejores que los del resto" (Silvia)

Por otro lado, quizá la precariedad se encuentre en los imaginarios que, popularizados en narrativas propias del cine, la televisión y otros ámbitos populares, colocan la identidad del artista en los márgenes de la sociedad. Dichas posiciones hablan de arquetipos vinculados a la genialidad, la locura, la incerteza, la incomprensión, la pobreza, etc. a pesar de las sumas de dinero que se mueve en determinados sectores del arte, como por ejemplo, en el ámbito de las galerías y las subastas.

\subsubsection{Transitando por espacios de enseñanza artística no reglada}

Leer los trabajos me llevó a tomar conciencia del papel que tenían las escuelas de arte dentro de la vida cultural de los estudiantes. Me sorprendió, por cantidad, las experiencias significativas que hablaban de motivaciones y aprendizajes fuera del ámbito reglado de la enseñanza. En este sentido, muchos eran los que complementaban su formación primaria y secundaria en centros ubicados en sus pueblos y ciudades de origen y en los barrios donde vivían.

A parte de la tendencias educativas regladas recibida en la escuela "la educación tiene múltiples registros y se entiende más allá de los muros de la escuela" (Bosch, 2005, p. 8), teniendo otras opciones como escuelas de pintura u otras actividades creativas. En un momento dado decidí apuntar-me a una escuela de pintura situada a las afueras de mi pueblo donde iba fuera del horario escolar. Iba dos días por semana durante dos horas con la intención de mejorar mi técnica y que me enseñasen a "dibujar correctamente" (...) en casi cualquier centro de arte no reglado se ofrece un aprendizaje guiado y pautado, en el cual se enseña una clases de técnicas particulares siguiendo un orden lógico y donde se aprende a base de la copia. (Marina)

He de hablar sobre el momento en que me dispuse a cambiar de academia para entrar a la escuela de arte. En ésta pasé desde los once años hasta que comencé la universidad. He de decir que la profesora que tuve durante todos aquellos años fue un gran referente para mí artísticamente y personalmente hablando. En esta escuela el método de enseñanza era todo lo contrario que la primaria. La profesora que tenía me enseñó las técnicas de pintura y dibujo. (Mireia)

Durante los dos de bachillerato aprendí muchas cosas pero una de las experiencias más placenteras fue al acabar y realizar un taller con un escultor (...) Con él aprendí cómo hacer una escultura, cómo tomar las medidas, cómo trabajar el barro. (...) La experiencia de conocerle en persona, saber qué piensa y qué me enseñe los conocimientos que tiene sobre escultura, pintura y dibujo, es sin duda, una sensación muy placentera intelectualmente y una gran fuente de influencia y conocimiento. (Marta)

De la lectura que realicé de los textos, pude interpretar la fuerza mediadora que implicaba asistir a dichos talleres para continuar la formación artística en la universidad. El grado de afinidad que se desprendía, me hacía percibir una doble dimensión en el aprendizaje: por un lado, la dominante técnica de la enseñanza desarrollada y, por otro, la noción de arte a la que predisponía las experiencias de aprendizaje.

Constituidas las relaciones pedagógicas bajo una estela de complicidad y motivación, las vivencias recordadas hablaban de instruirse en el dominio del dibujo, la pintura y la escultura, y donde la colocación 
del docente estaba en diferentes posiciones. Entre ellas, la dominante, estaba próxima al arte como saber dentro de un programa logocéntrico (Aguirre, 2000); esta tendencia quedaba definida bajo la dirección sabia y experta, la metodología precisa, y el desarrollo de ejercicios frecuentes. Por otro lado, por singular dentro del entramado, aparecía significativa la experiencia educativa de Mireia desarrollada a través de un aprendizaje basado en problemas.

Con nueve años, decidí comprometerme más con el dibujo y la pintura. Por este motivo decidí entrar en una escuela especializada en la enseñanza de artes plásticas. En ésta, no se hacían clases convencionales de dibujo donde se enseñaban las técnicas para saber dibujar y pintar. Se impartían clases más alternativas y que ayudaban a ejercitar la creatividad. Los trabajos se basaban en que el profesor planteaba una idea y tú tenías que crear, ya fuese una escultura, un dibujo o un cuadro que hablase sobre aquella idea. Aquella forma de enseñar la podríamos relacionar con la tendencia educativa de un aprendizaje basado en problemas. (Mireia)

Por otro lado, detecté un lugar consolidado heredado del contexto previo al universitario de una clara componente expresionista en torno al arte, a pesar de que su formación se ubicase bajo un programa logocéntrico. En esta línea son claros ejemplos las argumentaciones de Paula B., Mario y Silvia:

Siempre he dibujado mucho, desde muy pequeña y mis padres me influenciaron mucho para hacerlo, ya que pensaban que era la mejor manera que tenía de expresarme. (Paula B.)

Yo soy una persona introvertida y me costaba mucho expresar mis emociones y palabras. En este sentido, la danza fue una vía de escape que dejaba que me expresase de la manera más liberadora para mí. Esta expresividad que descubrir la transporté intuitivamente hacia otros campos con el dibujo y la pintura. Para mí, el arte ha sido siempre una mezcla entre evasión de la realidad y contacto conmigo mismo. (Mario)

Pienso que aquellos que nos introducimos en los estudios artísticos vocacionalmente son más sinceros, si tenemos que mostrar sentimientos los mostramos, si tenemos que mostrar nudos los mostramos. Mostramos nuestra personalidad con nuestro aspecto y no tenemos miedo de mostrarnos al mundo tal como somos, al menos en nuestro trabajo. (Silvia)

Las posiciones de Paula B, Mario, y Silvia estarían relacionadas con el arte como expresión y la educación artística como autoexpresión creativa (Aguirre, 2000). Esta manera de comprender la formación dejaba atrás la instrucción para promover la identificación con el trabajo mediante el uso libre de las facultades creativas. Al respecto, tal como argumenta Aguirre (2000, p. 189) "se trata de que el niño descubra y exteriorice sus emociones y sentimientos mediante la práctica artística. La imitación de modelos previos inhibe el desarrollo de estas facultades", entendiendo el dibujo como mera herramienta de expresión.

\subsubsection{Más allá de las artes visuales}

La revisión de las investigaciones de los estudiantes también me hizo tomar conciencia de que la relación con las artes tiene carácter multidisciplinar, moviéndose más allá de las artes visuales. Artes escénicas y performáticas como la danza, la música y el teatro, por ejemplo, habían acompañado a Carla que, influida por padres músicos, tocaba el piano y se convertía en una buena lectora de novelas; o el caso de Mario que de pequeño empezó a asistir a clase de danza. La investigación de Marina mostró uno de los ejemplos más significativos por su diversidad.

También estudié música. A los tres años comencé a ir a una coral, y a los cinco a tocar la flauta; pero estas disciplinas del arte acabaron cuando tenía siete u ocho años. Ya de mayor quise aprender a tocar la guitarra, lo intenté y lo dejé porque no le podía dedicar el tiempo necesario para avanzar en mi aprendizaje. Otra disciplina ha sido el teatro y la danza. Estudié durante siete años teatro y hasta hace poco hacía danza. De ésta, he probado muchas disciplinas, comencé hacia los tres años con danza clásica, después danzas populares catalanas, jazz, funky y contemporáneo. (Marina C.) 
Por otro lado, a Anna S. la influencia de su hermana y su tía le llevó a interesarse por las artes, compaginando de forma paralela la música y el manga. Y es que, en ocasiones, las artes visuales y la música emergen vinculadas a movimientos concretos; en este sentido, Carlos empieza a relacionarse con la pintura mural propia del grafiti y la canciones asociadas a la misma, el rap.

Siempre he sido una persona muy sensible y reservada, el graffiti me condujo al rap, un género de música urbana. Siempre escucho canciones en los cascos cuando dibujo, me ayuda a desconectar y solo estar por la hoja y mis pensamiento" (Carlos)

También otras artes habían protagonizado algunas de las relaciones con los estudiantes, en este caso, transitando a medio camino entre la literatura y las artes visuales. En esta línea, la experiencia de Paloma es un ejemplo de recorridos de ida y vuelta al alternar la escritura con la pintura y el dibujo.

Si bien el arte no es solo una expresión que se puede ejecutar de forma exclusivamente plástica, también me interesé por la escritura y la literatura. Esta razón fue uno de los motivos por los cuales me desvinculé de las artes puramente visuales. Expresarme a través de dibujos o pinturas pasó a segundo plano, ya que había encontrado otra manera de que, en aquel momento, me satisfacían más. (Paloma)

Las nuevas tecnologías también habían tenido un papel relevante en las relaciones con las artes. Primeramente, la televisión colocándolos en lugares de consumidores de series y películas de animación, y su consecuente extensión en la lectura de cómics y mangas japoneses. Blanca y Silvia, como muchos de los chicos y chicas de clase, recordaba haber visto los mismos programas infantiles y películas de animación en la televisión y en el cine.

Hablando de las influencias recibidas, hace falta destacar una que comparto con una de las compañera de clase: la televisión, y más concretamente el canal Super3. En la época en que miraba este canal se retrasmitían muchas series anime, de animación japonesa, como también películas de este estilo. Internet no era tan utilizado como ahora, y la televisión vino a tener una gran influencia y dejó una huella en todos aquellos niños que alrededor de aquellos años fuimos espectadores (Blanca)

Otra influencia que no puedo dejar de lado es la gran marca que me ha dejado la animación sobre todo Disney y el anime. Mi infancia se estructura a partir de las películas de Disney que veía con mis primos. Y el anime y el manga me han gustado desde hace muchos años, asistiendo durante cuatro años a clase de dibujo manga (Silvia)

Las nuevas tecnologías vinculadas a las redes sociales devienen, por un lado, como espacio expositivo donde se negocian las miradas de reconocimiento y, por otro, un lugar de aprendizaje donde compartir descubriendo nuevas herramientas y técnicas artísticas. Primeramente, como ámbito expositivo, Sara G. percibe el espacio virtual como "la prueba de fuego donde demostrar la verdad" al hacer público sus trabajos más satisfactorios en búsqueda del reconocimiento por parte de los demás. Como lugar de aprendizaje, las redes sociales presentan un amplio abanico de posibilidades que van desde el acceso a tutoriales a la participación activa en comunidades virtuales. Influida por este medio, Paloma recordaba su tránsito hasta llegar al ámbito de la fotografía.

La aparición de nuevas redes sociales y la rápida evolución de la tecnología favoreció esta desvinculación que sufrí con las artes plásticas, pero descubrí otra pasión paralela: la fotografía. A los 15 años pude adquirir una cámara de fotografías y eso pasó a ser, no mi medio de expresión, pero si un nuevo mundo artístico por experimentar. (Paloma)

De la revisión de las investigaciones comprendí el carácter diverso del bagaje artístico que traían los estudiantes antes de cursar grado de Bellas Artes. Los matices vinieron narrados en los textos, mostrando aquí tan solo un breve esbozo de lo que, a mi entender, resultó más significativo. 


\section{Conclusiones}

Soy consciente de que el giro autoetnográfico que propuse en la asignatura devino hacia una dominante sociología de la educación artística; creo que este hecho, es consecuencia de que, la mayoría principalmente, tenían una relación con el arte basada en la formación dada en la juventud de los estudiantes. Aunque interesante para sus vidas académicas, como dilema surge la disociación de los temas emergentes con las cuestiones más tradicionales que aborda la Sociología del Arte que, aunque trabajadas, quedaron relegadas a segundo plano. Revisar las trayectorias propias, supuso reconocerse como artistas en formación con la expectativa de encontrar su lugar actual; tal como creo, este podía ser un primer paso para vislumbrar algunas de las posibilidades que se abrirían a lo largo de sus trayectorias de formación y sus carreras profesionales.

Comprender la mediación de las miradas de los demás y las suyas propias, así como algunas cuestiones en torno a las inercias culturales heredadas creo que, en algunos de los casos, provocó un cambio en la comprensión de sí mismo como sujetos imbuidos en un sistema cultural del arte con un alto grado de competitividad. En este sentido, favorecer el trabajo autónomo implicó que muchos de los estudiantes saliesen de sus zonas de confort para, aunque fuese desde la resistencia, afrontasen nuevos dilemas en un ámbito que muta a la misma velocidad que la sociedad de la que forman parte.

\section{Referencias}

Aguirre, I. (2000) Teoría y práctica en educación artística. Ideas para una revisión pragmatista de la experiencia estética. Universidad Pública de Navarra. Pamplona.

Angulo, F. (1994) ¿A qué llamamos currículum? En: Angulo, J.F. y Blanco, N (ed.) Teoría y desarrollo del currículum. Ediciones Aljibe, Málaga.

Bourdieu, P., Darbel, A. (2003) El amor del arte. Los museos europeos y su política. Paidós Iberica (1969, $1^{\text {a }}$ ed.), Barcelona.

Cascante, C. (2004) La reforma de los planes de estudio. Un análisis político de los discursos sobre la formación inicial de los profesores de la educación. Revista Interuniversitaria de Formación de Profesorado, 18(3), pp. 145167.

Champagne, M.F., Clayton, T., Dimmitt, N., Matthew, L., Savage, W., Shaw, J., Stroupe, R., Thein, M.M., Walter, P. (2002) The assessment of learner autonomy and language learning. AILA Review, 15(0), pp. 45-55.

Chan, V. (2000) Fostering Learner Autonomy in an ESL Classroom. TESL Canada Journal, 18(1), pp. 75-86.

Ellingson, L., Ellis, C. (2008) Autoethography as Constructionist Project. En: Holstein, J.A., Gubrium, J.F. (ed.) Handbook of Constructionist Research, pp. 445-466. The Guilford Press, London.

Estruch, J. (2003) La perspectiva sociológica. En: Cardús (coord.) La mirada del sociólogo. Qué es, qué hace, qué dice la sociología, pp. 15-42. UOC, Barcelona.

Furió, V. (2012) Sociología del arte. Cátedra (2000, 1ª ed.), Madrid.

Goodson, I. (1991) La construcción social del currículum. Posibilidades y ámbitos de investigación de la historia del currículum. Revista de Educación, 295, pp. 7-37.

Heinich, N. (2003) La sociología del arte. Nueva Visión, Buenos Aires.

Johnston, B. (2013) El primer año de Universidad. Una experiencia positiva de transición. Narcea, Madrid.

Kenny, B. (1993) For more autonomy. System, 21(4), pp. 431-442. 
Marcelo, C. (1995) La formación del profesorado en el cambio educativo. EUB, Barcelona.

Marshall, B., Drummond, M.J. (2006) How teachers engage with Assessment for Learning: lessons from the classroom. Research Paper in Education, 21(2), pp.133-149.

Spry, T. (2001) Perfoming Autoethography: An Embodied Methodological Praxi. Qualitative Inquiry, 7(6), pp. 706732.

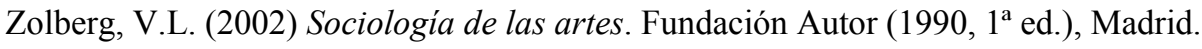

